http://jmscr.igmpublication.org/home/ ISSN (e)-2347-176x ISSN (p) 2455-0450 crossref DOI: https://dx.doi.org/10.18535/jmscr/v8i4.65

\title{
Blackening of Distal Fingers and Toes Associated with Pain: A Rare Case of Isoniazide Induced Lupus Cutaneous Vasculitis
}

Authors

\section{Dr Swapnil Kanire, Dr Ashok Bhupali, Dr Girish H, Dr Shriya G}

Department of Internal Medicine and Critical Care, Apple Saraswati Multispeciality Hospital and Research Institute Kolhapur, Maharashtra, India

\begin{abstract}
In this article, we present a case of a 27 year old male patient with symptoms and signs suggestive of vasculitis in fingers of upper as well as lower extremities. He was an old case of sputum positive pulmonary tuberculosis for which he received 6 months of antitubercular therapy with isonazide 300mg /day. Prompt diagnosis and treatment in cases of vasculitis is important to prevent irreversible damage to the limb as well as organs. This patient's all vasculitis workup was negative except ANA homogeneous pattern and antihistone antibody positive Reported here is a case of isoniazid-induced lupus presenting with vasculitis. This patient was treated with steroids and cyclophosphamide. He responded well to therapy. The existing literature on the subject is reviewed.

Keywords: Isoniazide, Blood vessel, Drug induced lupus, vasculitis.
\end{abstract}

\section{Introduction}

Vasculitis i.e. inflammation of blood vessels are heterogenous group of disorders ${ }^{1,2}$ may be present in arteries, veins or both. Vasculitis can occur in any part of the body and result in tissue necrosis. ${ }^{[1]}$ Cutaneous vasculitis i.e. inflammation of blood vessels in the skin ${ }^{3,4}$ may be present alone or it can be a sign of systemic vasculitis. ${ }^{[3]}$ Presentation of patient may range from mild condition to life threatening complication. ${ }^{[2]}$ Clinical presentation, laboratory and radiological investigations and histological findings play an important role in the diagnosis of vasculitis. ${ }^{\text {[2] }}$

Medications identified as definitely causing DrugInduced Lupus include procainamide, hydralazine, minocycline, penicillamine, isoniazid (INH), quinidine, anti-tumor necrosis factor (TNF) alpha therapy (most commonly with infliximab and etanercept), interferon-alfa, methyldopa, chlorpromazine, and practolol ${ }^{[4-6]}$.

Cutaneous manifestations of drug-induced discoid lupus has also been reported, but appears to be $\operatorname{rare}^{[7,8]}$.

There are no definitive tests or criteria for the diagnosis of drug-induced lupus; however, the diagnosis of drug-induced lupus is highly likely in the presence of history of taking one or more of the drugs known to be associated with this condition for at least one month and often much longer with the development of at least one clinical feature characteristic of SLE, spontaneous resolution of the clinical manifestations of the disease, typically within several weeks but sometimes up to several months after the offending drug has been discontinued ${ }^{[9]}$. 
Vasculitis develops in approximately 11 to 20 percent of patients with SLE ${ }^{[10,11,12]}$. The most common form, occurring in 10 to 15 percent of cases, is urticarial vasculitis. In contrast to urticaria, lesions of urticarial vasculitis may persist for more than 24 hours and frequently evolve into painful petechiae or purpura that may heal with hyperpigmentation.

Vasculitis may also affect small arteries, possibly resulting in microinfarcts of the tips of the fingers, the toes, the cuticles of the nail folds (splinter hemorrhages), and the extensor surface of the forearm and shin. The palms of the hand, soles of the feet, and area around the ankle are less commonly involved ${ }^{[13]}$.

We are presenting here case of Drug Induced Lupus presented as vasculitis.

\section{Case Presentation}

A 27 year male presented with chief complaints of bilateral distal fingers and toes blackening associated with pain over 1 month.

He was old case of sputum positive pulmonary tuberculosis for which he completed 6 months Antitubercular therapy one month before beginning of symptoms. He did not have any other comorbidities.

On examination, his pulse rate was 74 beats per minutes and blood pressure was $110 / 70 \mathrm{~mm} \mathrm{Hg}$. Peripheral pulses were present. No significant abnormality was detected on examination of cardiovascular, respiratory, central nervous system or per abdominal examination.

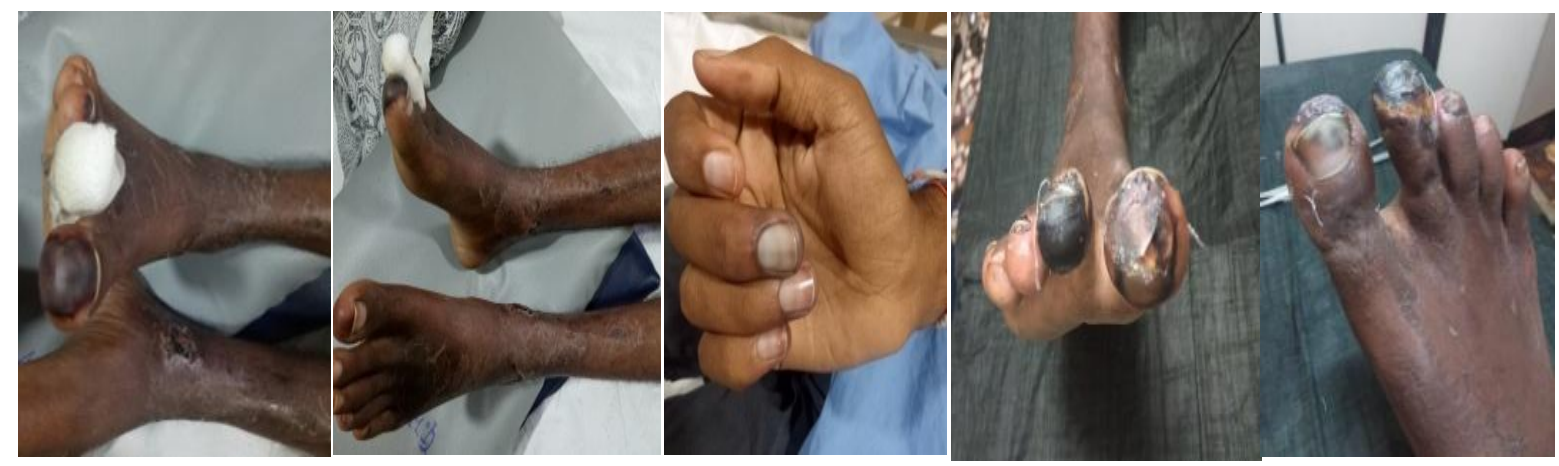

Figure 1: Blackening of fingers of upper and lower extremities

Laboratory investigations showed haemoglobin $12.7 \mathrm{gm} \%$, white blood cells $6800 / \mu \mathrm{L}$, platelet count $210,000 / \mu \mathrm{L}$, serum creatinine $1.05 \mathrm{mg} / \mathrm{dl}$, serum sodium $141 \mathrm{mEq} / \mathrm{L}$, serum potassium $3.89 \mathrm{mEq} / \mathrm{L}$, fasting blood glucose $88 \mathrm{mg} / \mathrm{dl}$, and post prandial blood glucose $109 \mathrm{mg} / \mathrm{dl}$. raised ESR and CRP.

HIV, HbsAg, HCV were negative.

Urin analysis was within normal limits.

Serum procalcitonin $1.5 \mathrm{ng} / \mathrm{ml}$.

Colour Doppler of both limbs and CT peripheral angiography showed presence of mild atherosclerotic changes.

Antineutrophil cytoplasmic antibody [diffuse cytoplasmic staining (C-ANCA), and perinuclear/ nuclear staining (P-ANCA)] were negative by ELISA method.
Cryoglobulins were negative.

Antinuclear antibody (ANA) was homogenously positive (1:1000). Antihistone antibody was positive. ANA profile from immunoblot was negative

Compliments C3 and C4 levels were within normal limits

The patient was treated with injection methylprednisolone $1 \mathrm{gm}$ per day for three days followed by oral prednisolone $1 \mathrm{mg} / \mathrm{kg} /$ day and cyclophosphamide $1 \mathrm{gm}$ once a month for 5 doses. Hydroxychloroquin is given for cutaneous and musculoskeletal manifestations 


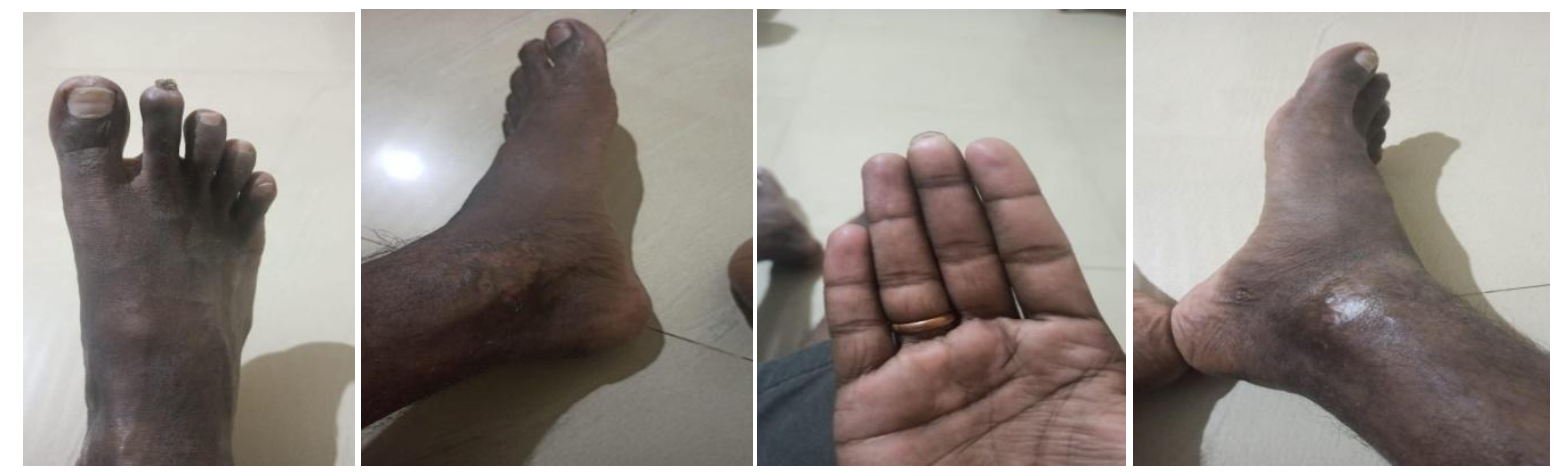

Resolution of the disease activity after therapy

\section{Discussion}

Patients with nonvasculitic disease may present with symptoms and findings that closely mimic various vasculitides. Perhaps most common are systemic rheumatic diseases, such as systemic lupus erythematosus, atherosclerotic disease, drug reactions, and vaso-occlusive processes. Among the most important diseases to exclude are infections and malignancies since immunosuppressive therapy could worsen these conditions and a delay in diagnosis can be extremely dangerous ${ }^{[14,15]}$.

Certain drugs may trigger an autoimmune response, which in some patients may result in a clinical syndrome with features similar to systemic or cutaneous lupus erythematosus, termed drug-induced lupus (DILE). Most commonly, these drugs induce autoantibodies without causing a clinical disorder. Drug-induced lupus has similarities to spontaneous (idiopathic) systemic lupus erythematosus (SLE), but there are some differences in clinical and immunologic features and in the frequency of such features.

Isoniazide (INH), one of the first-line antitubercular treatment drugs, is metabolized in the liver byacetylation and is excreted in urine. The lupus phenomenon, which has been reported with $\mathrm{INH}$, is an idiosyncratic reaction. Up to $25 \%$ of patients taking INH have detectable ANA titres, but only $1 \%$ develop systemic DILE, which requires taking dosages of 300 to $900 \mathrm{mg} / \mathrm{d}$ for a period ranging from 4 weeks to 14 months ${ }^{[16]}$.

Definite mechanism by which it occurs is unknown however, theory of genetic predisposition as a slow acetylator is accepted ${ }^{[16]}$.
Slow acetylators are homozygous for the recessive gene that controls expression of the liver enzyme acetyltransferase, which is involved in the metabolism of certain implicated drugs, such as procainamide, isoniazid and hydralazine ${ }^{[16]}$.

INH induced lupus presents with fever and pleuritis in half the number of cases and pericarditis in $30 \%$ cases $^{[17]}$. Our patient presented with blackening of hands and feet with digital ulceration. As per our knowledge it is not reported before.

Diagnosis of DILE is formed by detecting autoantibody levels. ANA is positive in $90 \%$ to 95 $\%$ of DILE cases ${ }^{[18]}$. ANA often persist for a greater duration than the symptoms and physical findings and in some patients autoantibodies may persist for a year or longer. Anti-histone antibodies are present in more than $95 \%$ of patients overall and is a hallmark for DILE. The anti-histone antibodies in DILE are primarily formed against a complex of the histone dimer H2A-H2B and DNA ${ }^{[18]}$. In contrast, the antihistone antibodies in idiopathic lupus are primarily directed against the $\mathrm{H} 1$ and $\mathrm{H} 2 \mathrm{~B}$ histone subunits ${ }^{[18]}$. Anti-DNA antibodies are also unusual ( $<5 \%$ cases) in DILE ${ }^{[26]}$. Anti-ds DNA antibodies are typically absent in DILE due to procainamide, hydralazine and isoniazid, but present in SLE ${ }^{[18]}$. Spontaneous resolution of the clinical manifestations of the disease occurs typically within several weeks but sometimes up to several months after the offending drug has been discontinued. This clinches the diagnosis of DILE and also differentiates it from SLE. 
Our patient had strongly positive ANA and antihistone antibodies which are a hallmark of DILE. Due to dramatic response noted after discontinuation of INH and uneventful introduction of steroids, a diagnosis of INH induced lupus was arrived at.

The initial step in treatment of DILE is to stop the offending drug. Systemic glucocorticoids may be required to treat cases of pericarditis and pleurisy ${ }^{[18]}$. In patients with more resistant disease, hydroxychloroquine can be used if constitutional, cutaneous and musculoskeletal symptoms persist $^{[18]}$. We do not rechallenge patients with a medication that has been identified as a likely cause of DILE in that individual.

\section{References}

1. Sharma P, Sharma S, Baltaro R, Hurley J. Systemic Vasculitis. Am Fam Physician. 2011;83:556-565

2. Khasnis A, Langford CA. Update on vasculitis. J Allergy ClinImmunol 2009; 123:1226-36

3. Cutaneous Vasculitis. British Association of Dermatologists. March 2017 http://www.bad.org.uk/shared/getfile.ashx id=289\&itemtype=document

4. Shakoor N, Michalska M, Harris CA, Block JA. Drug-induced systemic lupus erythematosus associated with etanercept therapy. Lancet 2002; 359:579.

5. De Rycke L, Kruithof E, Van Damme N, et al. Antinuclear antibodies following infliximab treatment in patients with rheumatoid arthritis or spondylarthropathy. Arthritis Rheum 2003; 48:1015.

6. Ioannou Y, Isenberg DA. Current evidence for the induction of autoimmune rheumatic manifestations by cytokine therapy. Arthritis Rheum 2000; 43:1431.

7. Cemil BC, Atas H, Canpolat F, et al. Infliximab-induced discoid lupus erythematosus. Lupus 2013; 22:515.
8. Yoshimasu T, Hiroi A, Uede K, Furukawa F. Discoid lupus erythematosus (DLE)-like lesion induced by uracil-tegafur (UFT). Eur J Dermatol 2001; 11:54

9. Vedove CD, Del Giglio M, Schena D, Girolomoni G. Drug-induced lupus erythematosus. Arch Dermatol Res 2009; 301:99.

10. Sontheimer RD, Gilliam JN. Systemic lupus erythematosus and the skin. In: Systemic Lupus Erythematosus, Lahita RG (Ed), Churchill Livingstone, New York 1992.

11. McCauliffe DP, Sontheimer RD. Cutaneous Lupus Erythematosus. In: The Clinical Management of Systemic Lupus Erythematosus, Second Edition, Schur PH (Ed), Lippincott, Philadelphia 1996.

12. Ramos-Casals M, Nardi N, Lagrutta M, et al. Vasculitis in systemic lupus erythematosus: Prevalence and clinical characteristics in 670 patients. Medicine (Baltimore) 2006; 85:95.

13. Ropes MW. Systemic Lupus Erythematosus, Harvard University Press, Cambridge, MA 1976.

14. Bateman H, Rehman A, Valeriano-Marcet J. Vasculitis-like Syndromes. Curr Rheumatol Rep 2009; 11:422.

15. Molloy ES, Langford CA. Vasculitis mimics. Curr Opin Rheumatol 2008; 20:29.

16. Pretel M, Marquès L, España A. Druginduced lupus erythematosus. Actas DermoSifiliográficas (English Edition) 2014;105 (1):18-30.

17. Siddiqui MA, Khan IA. Isoniazid-induced lupus erythematosus presenting with cardiac tamponade. Am J Ther. 2002;9(2):163-65

18. Merola J. Lupus-Like Syndromes Related to Drugs. In: Schur P, ed. by. Lupus Erythematosus Clinical Evaluation and Treatment. (1st ed) 2012:211-221. 